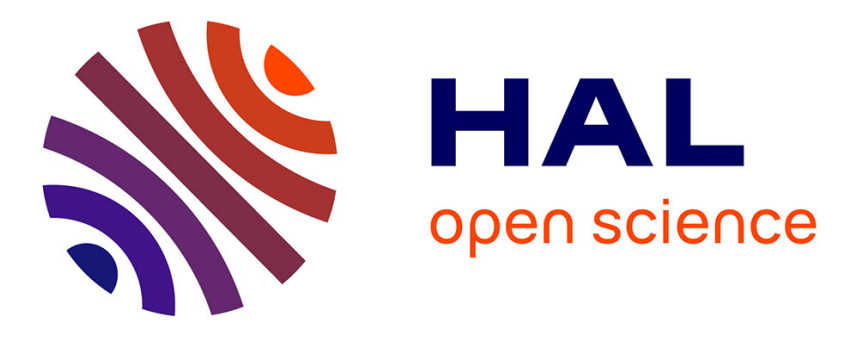

\title{
Distributed amplified ultra-stable signal quartz oscillator based
}

\author{
Patrice Salzenstein, Nathalie Cholley, A Kuna, Philippe Abbé, Franck
}

Lardet-Vieudrin, Ludvik Sodjr, Jacques Chauvin

\section{To cite this version:}

Patrice Salzenstein, Nathalie Cholley, A Kuna, Philippe Abbé, Franck Lardet-Vieudrin, et al.. Distributed amplified ultra-stable signal quartz oscillator based. Measurement - Journal of the International Measurement Confederation (IMEKO), 2012, 45 (7), pp.1937 - 1939. 10.1016/j.measurement.2012.03.035 . hal-03223645

\section{HAL Id: hal-03223645 \\ https://hal.science/hal-03223645}

Submitted on 11 May 2021

HAL is a multi-disciplinary open access archive for the deposit and dissemination of scientific research documents, whether they are published or not. The documents may come from teaching and research institutions in France or abroad, or from public or private research centers.
L'archive ouverte pluridisciplinaire HAL, est destinée au dépôt et à la diffusion de documents scientifiques de niveau recherche, publiés ou non, émanant des établissements d'enseignement et de recherche français ou étrangers, des laboratoires publics ou privés. 


\title{
Distributed amplified ultra-stable signal quartz oscillator based
}

\author{
P. Salzenstein ${ }^{1}$, N. Cholley ${ }^{1}$, A. Kuna ${ }^{2}$, P. Abbé ${ }^{1}$, F. Lardet-Vieudrin ${ }^{1}$, L. Sojdr ${ }^{2}$ \\ and J. Chauvin ${ }^{3}$ \\ ${ }^{1}$ Franche Comté Eléctronique Thermique Optique Sciences et Technologies, \\ CNRS, 26 Chemin de l'épitaphe, F25000 Besançon, France, \\ patrice.salzenstein@femto-st.fr \\ ${ }^{2}$ Institute of Photonics and Electronics, Academy of Sciences, Chaberska 57, \\ 18251 Prague 8, Czech Republic \\ ${ }^{3}$ Oscilloquartz, 16 rue des Brevards, Neuchâtel 2002, Switzerland
}

Abstract: The aim of this communication is to present the performances of 5 $\mathrm{MHz}$ distributed ultra-stable system, based on ultra-stable Boitiers à Vieillissement Amélioré (BVA) oscillator. We demonstrated flicker frequency modulation (FFM) floor better than $4.5 \times 10^{-14} \pm 2.5 \times 10^{-15}$ at $12 \mathrm{~s}$ with an intrinsic noise floor about $6 \times 10^{-15}$ at $1 \mathrm{~s}$ with a $\tau^{-1 / 2}$ time integration dependence slope.

Keywords: Short term frequency stability measurements, flicker frequency modulation, Radio frequency, Phase noise, time-frequency.

1. Introduction: For spectral density of phase noise and short term stability measurements, stable reference sources are needed. With recent progress in ultra-stable radio frequency sources [1-3], noise of distribution amplifiers must be the weakest possible to keep the noise floor the lowest. Thus we achieve a high performance distribution amplifier. For a 1s integration time, it must be 
better than $2.5 \times 10^{-14}$ [1]. A distribution amplifier is realized and its design and performances are presented in the following part of this letter. An ultra-stable Boitiers à Vieillissement Amélioré (BVA) oscillator is then integrated and is fully characterized to validate the system at its highest level. Performances as lower as $4.5 \times 10^{-14}$ are found for the flicker frequency modulation (FFM) floor on oscillator and distributed signal in terms of frequency stability. These results are presented in the latter part.

2. Design and characterization of the system: The design is optimized for low noise signals to be delivered at 5 and $10 \mathrm{MHz}$ to be integrated with a Boitier à Vieillissement Amélioré (BVA) reference oscillator. A picture of the distribution amplifier system (DAS) is shown on figure 1 , and the DAS is schematically represented on figure 2. A good isolation is expected and it is necessary that output power keep a good flatness for both 5 and $10 \mathrm{MHz}$ outputs. Our purpose consists in optimizing the performances of this device to allow integration of the best available commercial BVA oscillators. The quartz resonator is there mechanically stabilized by non-adherent electrodes. It presents a double copper oven structure that considerably helps for thermal isolation of the quartz resonator, especially because it is compacted in a dewar flask. The first oven is mechanically hold by a rigid composite material. The internal oven control card is placed in the second copper oven. The external card is placed inside the dewar flask. Moreover this system deliver two $5 \mathrm{MHz}$ and two $10 \mathrm{MHz}$ outputs. An amplifier and a x2 multiplier based on an hybrid junction are placed on one arm to deliver the $10 \mathrm{MHz}$ output signals. The amplifier stage is significantly improved thanks to the multiplication by 
two, that is the doubling. It allows an optimal performance in power, combined with an excellent noise factor. It is achieve by using the rectifier effect of a diode bridge. To reject harmonics, signal is filtered before the input and after multiplication and amplification. Spurious peaks are especially filtered by low pass filters for 20 and $30 \mathrm{MHz}$. For a $+7 \mathrm{dBm} 5 \mathrm{MHz}$ input signal, we then respectively achieve $-41,-76$ and $-91 \mathrm{dBc}$ for 10,20 and $30 \mathrm{MHz}$ at the $5 \mathrm{MHz}$ distributed output.

A set of two distribution amplifiers is realized for characterization of the floor of both of these boards. We deduce their performances by analyzing the results of $S_{\Phi}$, the spectral density of phase noise measurement. The measurement setup is given in figure 3. $\mathrm{S}_{\Phi}(1 \mathrm{~Hz})=-141.4 \mathrm{~dB} \cdot \mathrm{rad}^{2} / \mathrm{Hz}$ at $5 \mathrm{MHz}$ and -141 $\mathrm{dB} \cdot \mathrm{rad}^{2} / \mathrm{Hz}$ at $10 \mathrm{MHz}$ with a $1 / \mathrm{f}$ slope. It is obtained by measuring the phase noise of two similar outputs of the distribution amplified quartz based system. We deduce the value considering that the two output have identical contribution to the noise. For a $1 / f$ slope in the spectral domain, we use the following relation referenced (1) to deduce $\sigma_{y}(\tau)$ versus the spectral density of phase noise [4]:

$$
\left.\sigma_{y}^{2}(\tau)=\left[h_{1} /\left(4 \pi^{2} \cdot \tau^{2}\right)\right] \cdot\left[9 / 2+3 \operatorname{Ln}\left(2 \pi F_{h} \tau\right)\right)-L n 2\right]
$$

where $h_{1}$ is the coefficient of the slope at $1 \mathrm{~Hz}, \tau$ the integration time, $F_{h}$ cutoff frequency of the noise.

This equation allows us to estimate the frequency stability in terms of Allan variance, $\sigma_{\mathrm{y}}{ }^{2}(\tau)=1.39 \times 10^{-14}$ at $1 \mathrm{~s}$ for the $5 \mathrm{MHz}$ signal, and $\sigma_{\mathrm{y}}{ }^{2}(\tau)=7.29 \times 10^{-15}$ at $1 \mathrm{~s}$ for $10 \mathrm{MHz}$. These results are very closed to the state-of-the-art results [5-8] and are low enough for distribution of the best BVA oscillators [1]. 
3. Frequency stability measurements on system integrated oscillator: For determining the performance of the system in terms of short term frequency stability, main principle is based on Dual Mixer Time Difference Multiplication (DMTDM) [8-11] with a beat frequency of $5 \mathrm{~Hz}$. Each measure gives 10,000 samples [2, 3] and they are separated by a basic $200 \mathrm{~ms}$ integration time. For evaluating the limit of the bench, we test the rejection of one BVA Oscillator, to be able to deduce a flicker phase of $6 \times 10^{-15}$ at $1 \mathrm{~s}$ with a $\tau^{-1 / 2}$ slope. Fig. 4 represents the limit of the measuring system. It is clearly negligible in the 1$100 \mathrm{~s}$ region where flicker floor is measured. The direct output of the selected BVA oscillator number \#199 is first measured on the DMTDM bench and then integrated with the distribution amplifier as described above. It is measured with in comparison with the best reference oscillator previously demonstrated to present a $2.5 \times 10^{-14} \mathrm{FFM}$ floor [1], noted 'BVA Ref.' on the legend of Fig. 3. It has to be underlined that thanks to the fact we have measured the BVA \#199 previously comparatively to the best BVA, we can be sure of our results with the present experiment. The curve represented in Fig. 5 shows a FFM floor at $4.5 \times 10^{-14} \pm 2.5 \times 10^{-15}$ for a $12 \mathrm{~s}$ integration time at the distributed output of the integrated system. This result is mainly due to the contribution of the intrinsic noise floor of the $5 \mathrm{MHz}$ BVA \#199 oscillator set as the reference distributed through the DAS. It has to be underlined that those oscillators and DAS were carried under batteries during transport, as each short disconnection can have an effect on the value of the stability at such low levels. 
4. Conclusion: Thanks to the use of the best reference signal for evaluate the performance of the designed and realized DAS, measurements clearly show that the developed DAS is accurate for the new generation of $5 \mathrm{MHz}$ state-ofthe-art BVA oscillators appearing in the recent period. To our knowledge, it is the first time that such performances have been measured for a DAS in time domain.

Acknowledgement: This work was supported by the French national metrology institute (LNE) under contract number LNE/DRST 107002.

\section{References}

[1] P. Salzenstein, A. Kuna, L. Sojdr, J. Chauvin, Significant step in ultra-high stability quartz crystal oscillators, Electron. Lett. 46(21) (2010) 1433-1434.

[2] A. Kuna, J. Cermak, L. Sojdr, P. Salzenstein, F. Lefebvre, Lowest FlickerFrequency Floor Measured on BVA Oscillators, IEEE Trans. on Ultrason. Ferroelec. Freq. Contr. 57(3) (2010) 548-551.

[3] P. Salzenstein, A. Kuna, L. Sojdr, F. Sthal, N. Cholley, F. Lefebvre, Frequency stability measurements of ultrastable BVA resonators and oscillators, Electron. Lett. 46(10) (2010) 686-688.

[4] J. A. Barnes, A. R. Chi, L. S. Cutler, D. J. Healey, D. B. Leeson, T. E. McGuniga, J. A. Mullen, W. L. Smith, R. L. Sydnor, R. F. C. Vessot, G. M. R. Winkler, Characterization of Frequency Stability, IEEE Trans. on Instr. and Meas., IM-20(2) (1971) 105-120.

[5] C. W. Nelson, F. L. Walls, M. Sicarrdi, A. DeMarchi, A new 5 and $10 \mathrm{MHz}$ high isolation distribution amplifier, IEEE Freq. Contr. Symp. Boston. USA. (1994) 567-571.

[6] TimeTech, $5 \mathrm{MHz}$ frequency distribution amplifier $\mathrm{n}^{\circ} 10219$ (2006) http://www.timetech.com/

[7] Quartzlock, 1-100 MHz Distribution amplifier, A5 series (2007) http://www.quartzlock.com/ 
[8] G. Brida, High resolution frequency stability measurement system, Review of Scientific Instr. 73(5) (2002) 2171-2174.

[9] L. Sojdr, J. Cermak, G. Brida , Comparison of high-precision frequencystability measurement systems, Proc. of the IEEE Freq. Contr. Symp. \& European Freq. and Time Forum. Tampa. USA, (2003) 317-325.

[10] K. Mochizuki, M. Uchino, T. Morikawa, Frequency-stability measurement system using high-speed ADCs and digital signal processing, IEEE Trans. on Instr. and Meas., 56(5) (2007) 1887-1893.

[11] J. R. Norton, J. M. Cloeren, P. G. Sulzer, Brief history of the development of ultra-precise oscillators for ground and space applications, Proc. of the IEEE Int. Freq. Contr. Symp., (1996) 47-57.

\section{Figure captions:}




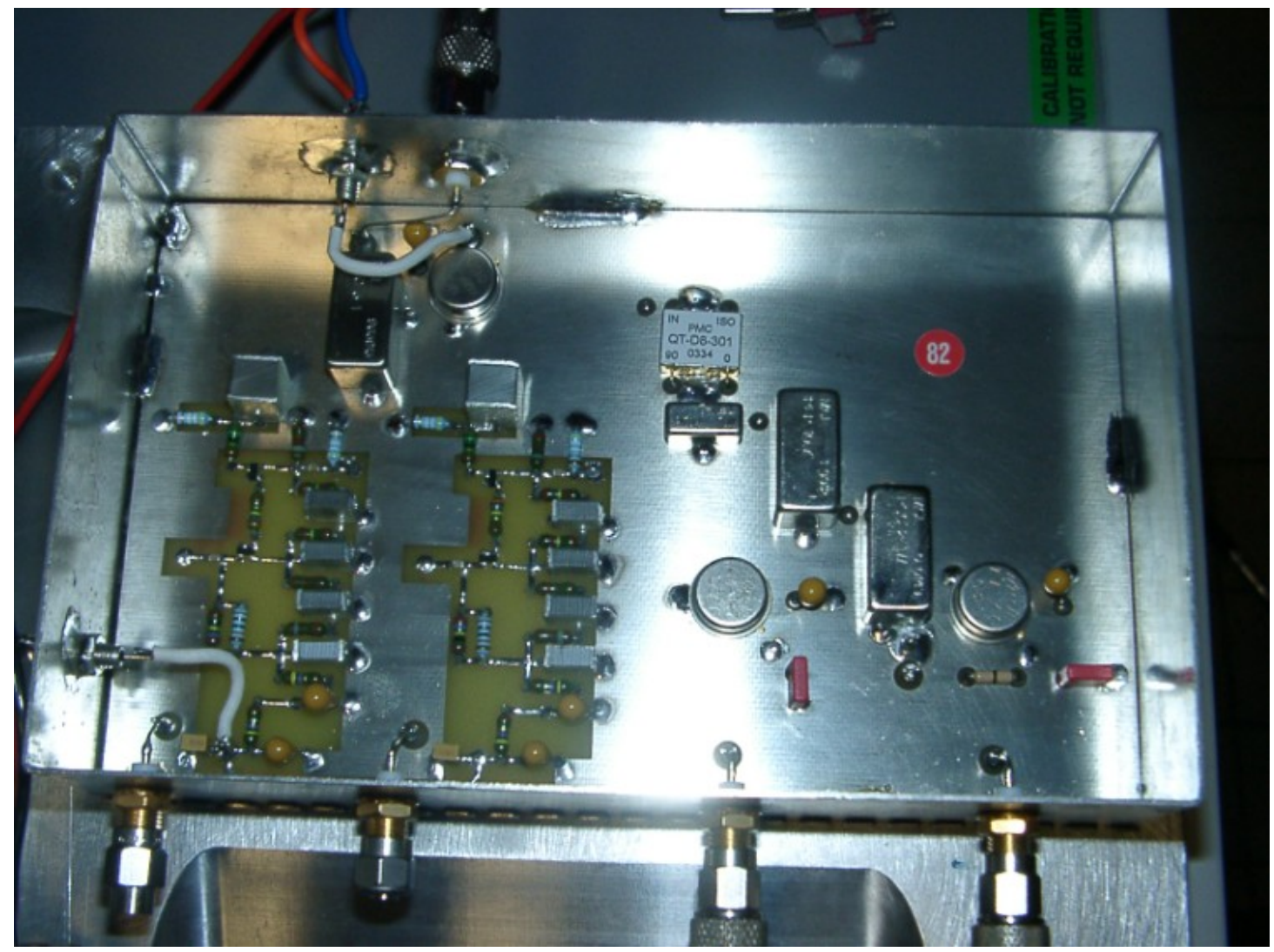

Fig. 1 Picture of the distribution amplifier board

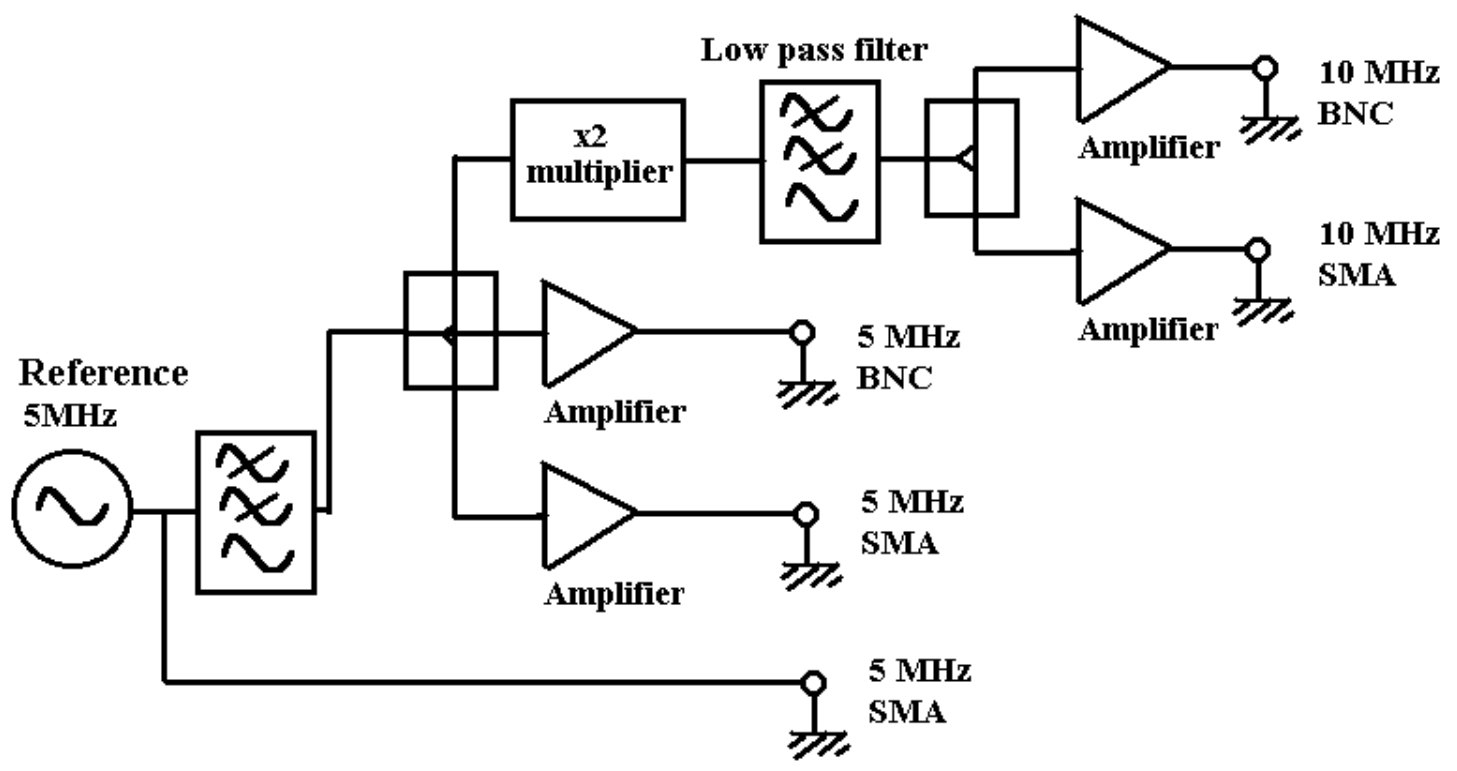

Fig. 2 Diagram of the Distribution amplifier circuit 


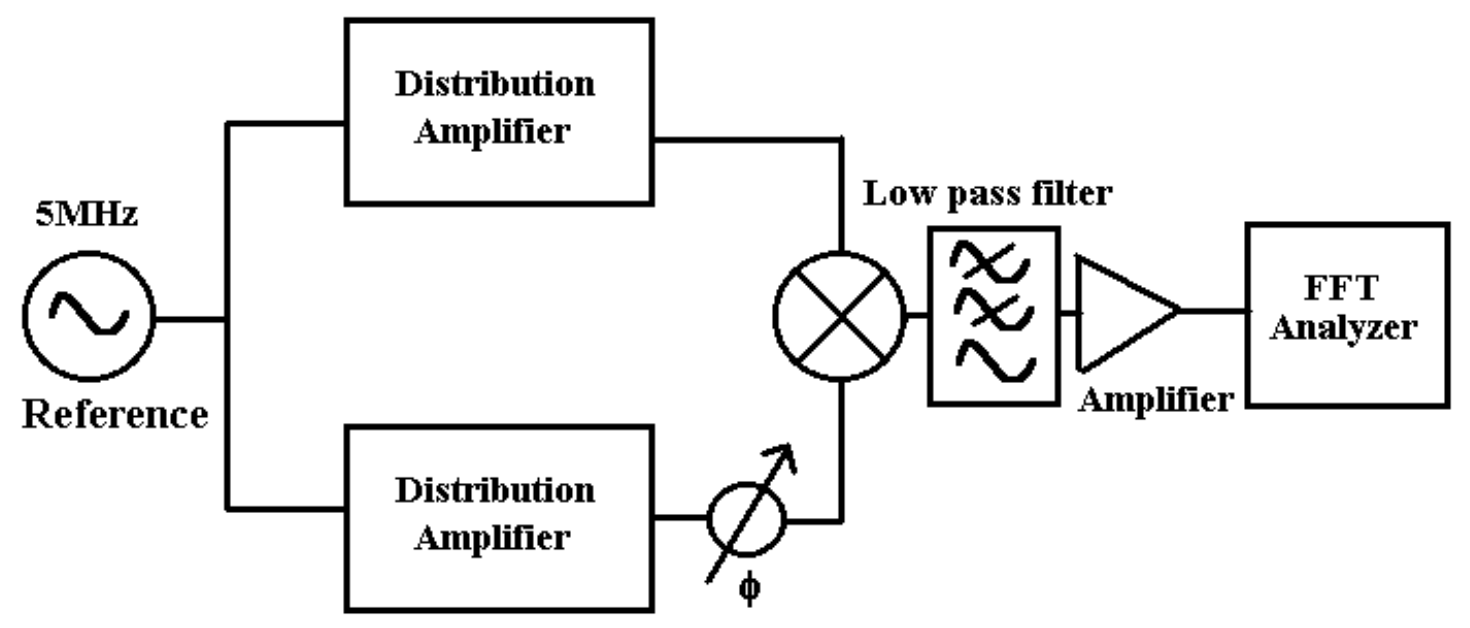

Fig. 3 Phase noise measurement setup

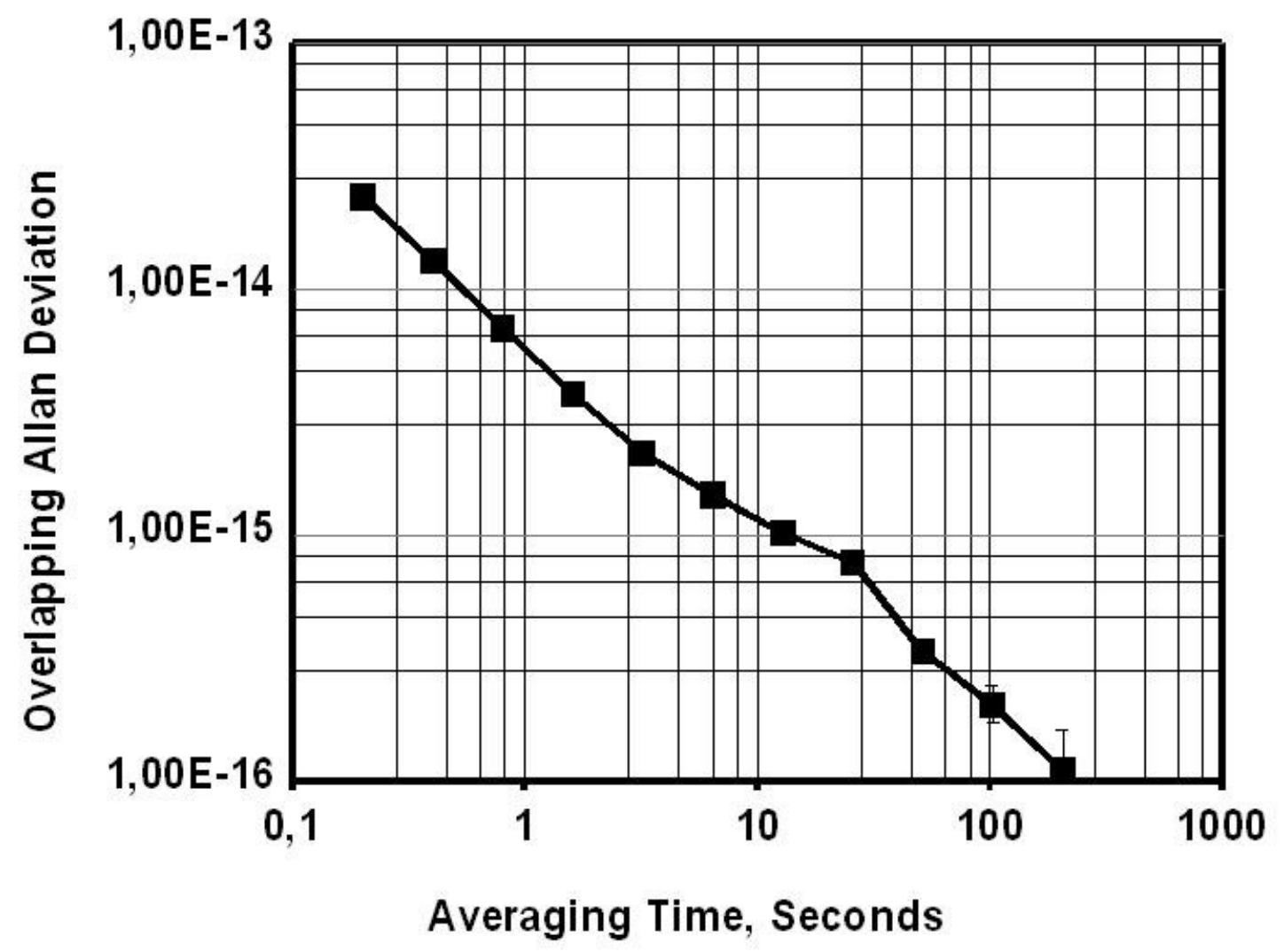

Fig. 4 Bench limit 


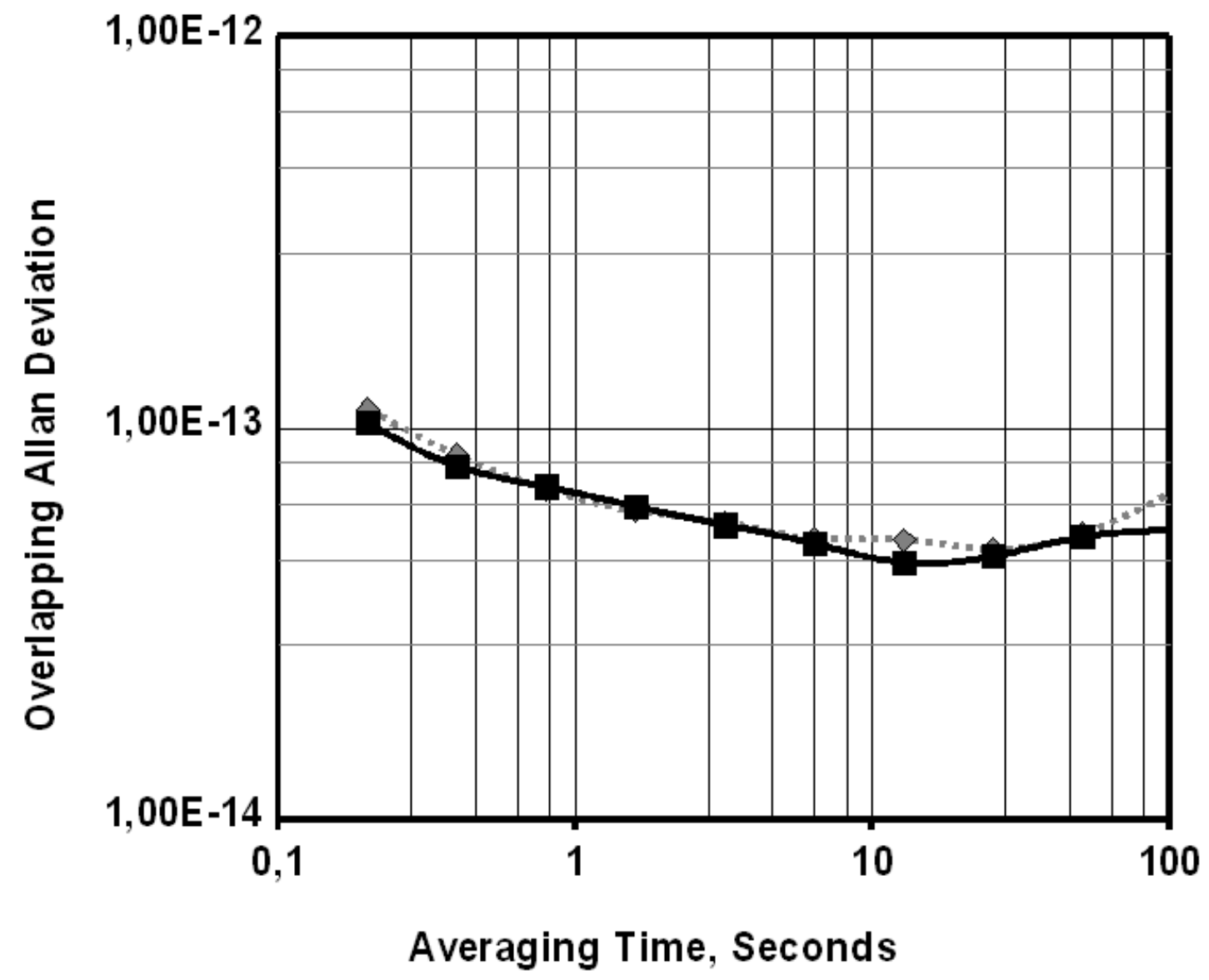

Fig. 5 Frequency stability measurements on DAS $5 \mathrm{MHz}$ output versus BVA reference

Rhombus: BVA Ref. versus BVA \#199 direct output

Square: $\quad$ BVA Ref. versus BVA \#199 distributed output 